\title{
Caracteres anatômicos do segmento caulinar em espécies da subfamília Opuntioideae (Cactaceae)
}

\author{
Emilia Cristina Pereira de Arruda ${ }^{1}$ e Gladys Flavia de A. Melo-de-Pinna ${ }^{2,3}$
}

Recebido: 11.02.2014; aceito: 4.12.2014

\begin{abstract}
Anatomical characters of stem segments in species of Opuntioideae (Cactaceae) subfamily). This work presents a general anatomical characterization of the stem segments of four species of Opuntioideae with emphasis on the dermal and ground tissue systems, and a review of the anatomical studies for the subfamily. Some characters are distinctive for the studied species, such as: stomata position in the same level of the remaining epidermal cells, occurrence of papillose epidermis and trichomes, stomata type, cell type of the palisade cortex, and occurrence of mucilaginous channel next to the phloem. In conclusion, our results show that some anatomical aspects on the dermal and ground systems are useful in the diagnosis of species. Furthermore, original data about distribution of medullary cells with secondary wall thickening are described in Opuntia or Opuntioideae. Keywords: papillose epidermis, wide-band tracheids
\end{abstract}

RESUMO - (Caracteres anatômicos do segmento caulinar em espécies da subfamília Opuntioideae (Cactaceae)). Este trabalho apresenta uma caracterização anatômica dos segmentos caulinares de quatro espécies de Opuntioideae com ênfase nos sistemas de revestimento e fundamental, e uma revisão dos estudos anatômicos para a subfamília. Alguns caracteres permitiram distinguir as espécies examinadas, tais como: posição dos estômatos em relação às demais células da epiderme, ocorrência de epiderme papilosa e tricomas, tipo de estômato, formato da célula do parênquima cortical, ocorrência de canais secretores de mucilagem adjacentes ao floema. Concluindo, nossos resultados mostram que alguns aspectos dos sistemas de revestimento e fundamental são úteis na diagnose das espécies. Além disso, novos dados sobre a distribuição de células medulares com espessamento de parede secundária são descritos em Opuntia ou Opuntioideae.

Palavras-chave: epiderme papilosa, traqueídes com amplo espessamento de parede

\section{Introdução}

Opuntioideae constitui uma das quatro subfamílias tradicionalmente reconhecidas em Cactaceae, apresentando cerca de 220-350 espécies com hábitos arborescente, arbustivos ou cespitosos, com distribuição no Canadá, América do Norte, Caribe, América Central e do Sul (Anderson 2001, Wallace \& Dickie 2002). Embora seja monofilética, a subfamília apresenta circunscrição bastante controversa, principalmente dentro do gênero Opuntia (Griffith \& Porter 2009). De acordo com Anderson (2001), os principais gêneros atualmente reconhecidos são: Austrocylindropuntia, Brasiliopuntia, Consolea, Cumulopuntia, Cylindropuntia, Grusonia (incluindo Corynopuntia), Maihuenia, Maihueniopsis (incluindo
Puna), Miqueliopuntia, Opuntia (incluindo Nopalea), Pereskiopsis, Pterocactus, Quiabentia, Tacinga, Tephrocactus e Tunilla.

Como a maioria dos demais representantes da família, espécies de Opuntioideae são comumente encontradas em ambientes áridos, cuja capacidade de habitá-los é favorecida, principalmente, pela presença de uma estrutura interna altamente especializada para o armazenamento de água e nutrientes (Conde 1975, Gibson \& Nobel 1986).

O sistema de revestimento nas Cactaceae é representado pela epiderme juntamente com uma a várias camadas de células hipodérmicas responsáveis pela proteção do parênquima clorofiliano situado imediatamente interno a este tecido (Gibson \& Nobel 1986, Darling 1989). Do ponto de vista fisiológico,

1. Universidade Federal de Pernambuco, Departamento de Botânica, Centro de Ciências Biológicas, 50670-901 Recife, PE, Brasil

2. Universidade de São Paulo, Departamento de Botânica, Instituto de Biociências, Caixa Postal 11461, 05422-970 São Paulo, SP, Brasil

3. Autor para correspondência: gfmpinna@usp.br 
o conhecimento deste sistema é essencial para o entendimento dos mecanismos que auxiliam na sobrevivência destas plantas em ambientes áridos (Nobel 2002). Além da importante função fisiológica desempenhada por estes dois tecidos, o sistema de revestimento representa ainda uma das principais fontes de dados diagnósticos na família, sendo os principais estudos realizados com representantes da subfamília Cactoideae (Terrazas \& Arias 2003).

Loza-Cornejo \& Terrazas (2003) destacaram a importância taxonômica de caracteres anatômicos utilizados na descrição de espécies de Cactoideae da América do Norte, como o aspecto da epiderme em seção transversal, espessura da cutícula, largura das células epidérmicas, número de camadas da hipoderme, além da presença e do tipo de cristais, como por exemplo, corpos de sílica que muitas vezes são utilizados para resolver classificações controversas, como observado em algumas espécies de Echinocereus. Ainda com representantes de Cactoideae, Calvente et al. (2008) destacaram alguns caracteres importantes na separação de espécies de Rhipsalis Gaertn., como a posição dos estômatos e o formato das células epidérmicas.

Para Opuntioideae os trabalhos estão concentrados na década de 1970, com espécies de Cylindropuntia (Hamilton 1970) e de Opuntia Mill. (Conde 1975). Neste último, o autor descreveu em cinco espécies os caracteres anatômicos relacionados aos sistemas de revestimento, fundamental e vascular. Mesmo com a grande representatividade das Opuntioideae o número de espécies estudadas sob o aspecto anatômico ainda é pequeno.

Neste trabalho são apresentados dados anatômicos dos sistemas de revestimento e fundamental em segmentos caulinares de quatro espécies de Opuntioideae, e uma revisão da literatura para a subfamília, com novas contribuições aos estudos anatômicos de Cactaceae.

\section{Material e métodos}

Para o presente estudo foram utilizadas quatro espécies de Opuntioideae (Austrocylindropuntia subulata (Muehlenpfordt) Backeb., Opuntia microdasys Lehmann, Opuntia monacantha (Willd.) Haw. e Opuntia rufida Engelm) e foi realizada uma revisão da literatura sobre anatomia dos sistemas de revestimento e fundamental para a subfamília.

Amostras das regiões apical, mediana e basal de três segmentos caulinares maduros das quatro espécies selecionadas, foram fixadas em FAA50 (formaldeído, ácido acético, etanol 50\%) e desidratadas em série etanol-butanólica 50\%-100\%-Butanol Puro (Johansen 1940). Em seguida, foram incluídas em parafina, emblocadas e seccionadas transversal e longitudinalmente em micrótomo rotativo (ReicherttJung, Autocut 2040). As seções obtidas foram coradas com azul de astra 1\% e safranina 1\% (Kraus et al. 1998), e em seguida montadas lâminas permanentes com Entellan ${ }^{\circledR}$ (Purvis et al. 1964).

Para a análise da epiderme em vista frontal foi realizada a técnica de dissociação com uso da solução de peróxido de hidrogênio e ácido acético 1:1 (Franklin 1945). O material foi corado com safranina $1 \%$ aquosa, e as lâminas semi-permanentes montadas em glicerina 50\% (Purvis et al. 1964).

A epiderme em vista frontal foi analisada em Microscopia Eletrônica de Varredura (MEV), sendo o material desidratado em série etanólica (50\%-100\%), submetido a ponto crítico e posteriormente metalizado, seguindo metodologia descrita por Silveira (1989).

Teste histoquímico para mucilagem foi realizado utilizando ácido tânico e cloreto de ferro III (Pizzolato \& Lillie 1973).

As principais estruturas foram registradas no Sistema de Digitalização de Imagens (IM50) acoplado ao microscópio Leica DMLB.

\section{Resultados e Discussão}

A tabela 1 mostra uma lista de caracteres dos sistemas de revestimento e fundamental em segmentos caulinares de espécies de Opuntioideae, incluindo dados da literatura e os obtidos no presente estudo.

Em todas as espécies estudadas, o sistema de revestimento primário no caule é representado pela epiderme unisseriada revestida por cutícula (tabela 1, figuras 1a-b). Nos cactos "não-pereskia", os quais dependem da realização da fotossíntese no sistema caulinar, o sistema de revestimento predominante no ápice e na região mediana é a epiderme (Gibson \& Horak 1978, Mauseth 1996, 1999). Nestes cactos a epiderme permanece funcional por décadas, controlando as trocas gasosas necessárias à realização do processo fotossintético (Darling 1989).

Em Austrocylindropuntia subulata, Opuntia rufida e $O$. monacantha a epiderme apresenta aspecto plano com os estômatos situados no mesmo nível das demais células epidérmicas (figura 1a) em todas as regiões analisadas, corroborando o mencionado por outros autores para Cactaceae (Conde 1975, Eggli 


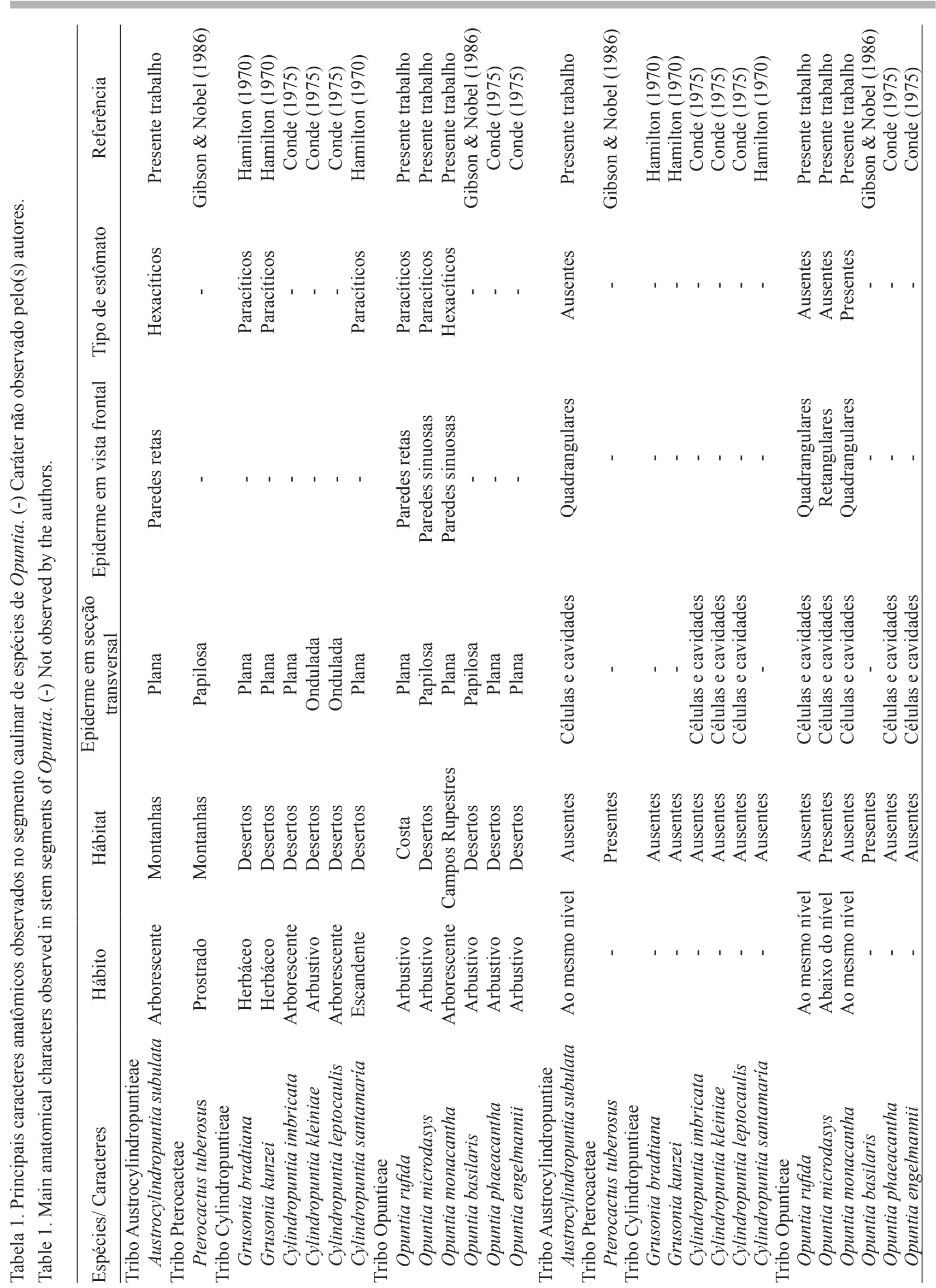


1984, Darling 1989, Calvente et al. 2008). Esta localização superficial dos estômatos, provavelmente, favorece rápidas trocas gasosas durante sua abertura, podendo representar uma adaptação ao mecanismo fotossintético CAM (Gibson \& Horak 1978, Gibson \& Nobel 1986).

Em outras espécies os estômatos situam-se abaixo das células epidérmicas, podendo representar uma estratégia adaptativa a perda excessiva de água por evaporação (Fahn \& Cutler 1992). Em Opuntia microdasys, a epiderme tem aspecto papiloso, com estômatos situados em pequenas depressões envoltas pelos tricomas (figuras1b-h). Dentre as espécies de Opuntioideae já estudadas (ver tabela 1), é descrita a ocorrência de epiderme papilosa apenas em Pterocactus tuberosus (Pfeiff.) Britton \& Rose), representante da tribo Pterocacteae (Gibson \& Nobel 1986). Nas demais espécies, o arranjo das células
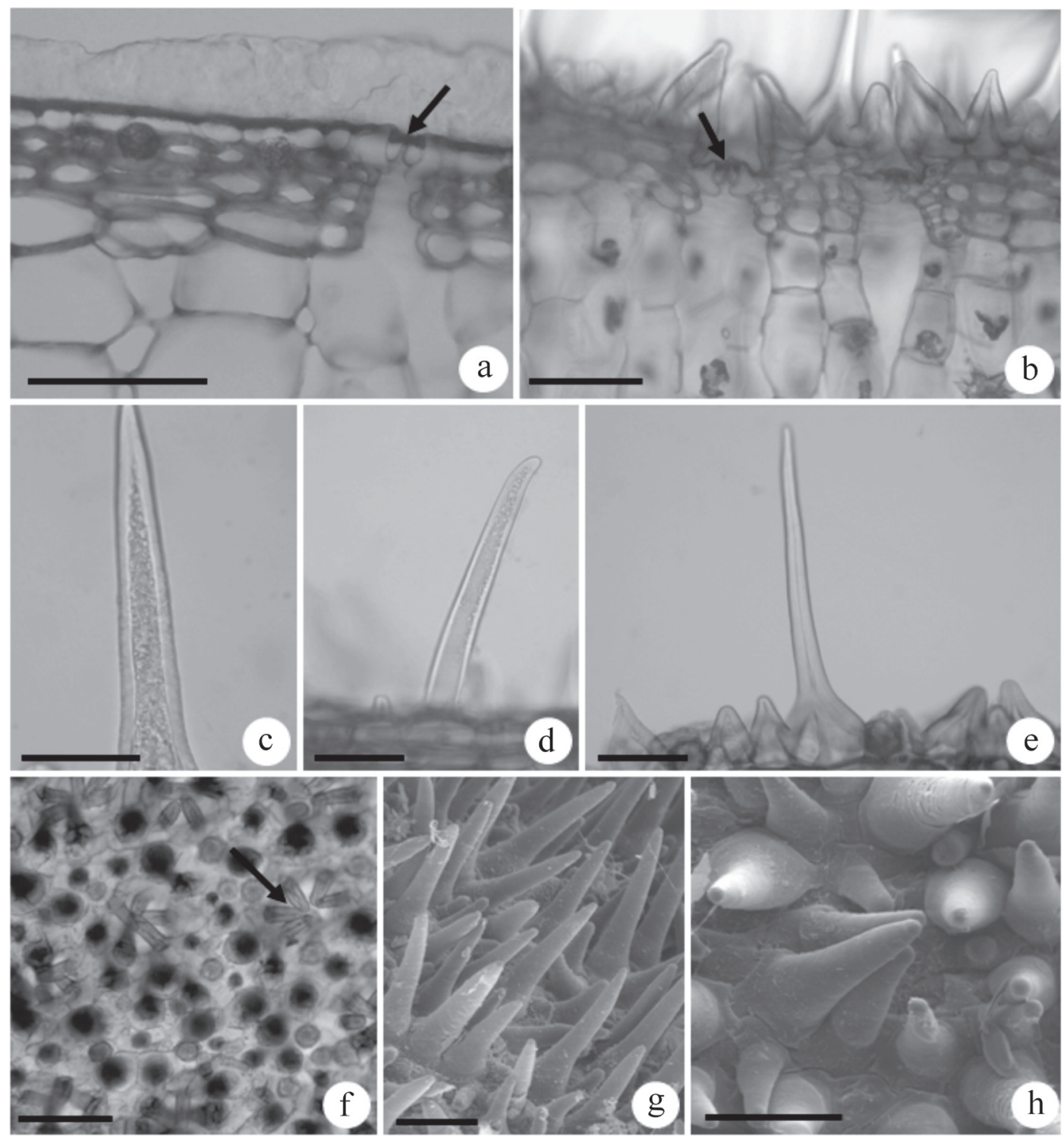

Figura 1. Secções transversais do segmento caulinar. a. Opuntia monacantha, epiderme unisseriada e a hipoderme multisseriada. b. Opuntia microdasys, epiderme papilosa com estômatos (seta). c-e. Tricomas unicelulares em Opuntia microdasys. f-h. Epiderme do segmento caulinar de Opuntia microdasys. f. Material observado em microscopia óptica, arranjo dos tricomas (seta). g-h. Microscopia Eletrônica de Varredura (MEV), -tricomas e seu arranjo em torno dos estômatos. Barras = $40 \mu \mathrm{m}$ (a, c-e); $80 \mu \mathrm{m}$ (b, f); $375 \mu \mathrm{m}(\mathrm{g}) ; 35 \mu \mathrm{m}$ (h).

Figure 1. Cross sections of the stem segments. a. Opuntia monacantha showing uniseriate epidermis (arrow) and multiseriate hypodermis. b. Opuntia microdasys. Note pappilose epidermis with stomata (arrow). c-e. Unicellular trichomes in Opuntia microdasys. f-h. Epidermis of the stem segment of Opuntia microdasys. f. Surface view in optical microscopy. Note arrangement of trichomes (arrow). g-h. Scanning Electron Microscopy (SEM), showing trichomes covering the stomata. Bars = $40 \mu \mathrm{m}$ (a, c-e); $80 \mu \mathrm{m}(\mathrm{b}, \mathrm{f}) ; 375 \mu \mathrm{m}(\mathrm{g}) ; 35 \mu \mathrm{m}(\mathrm{h})$. 
epidérmicas é bastante variável, mesmo dentro de cada tribo, como por exemplo, na tribo Cylindropuntieae onde Cylindropuntia leptocaulis FM. Knuth e $C$. kleiniae (DC.) FM. Knuth apresentam epiderme ondulada, e nas demais, a epiderme é plana (tabela 1).

Além das células papilosas curtas, em $O$. microdasys ocorrem também tricomas unisseriados unicelulares (figuras 1b-h). Segundo Loza-Cornejo \& Terrazas (2003), em Cactaceae é comum os tricomas no caule serem descritos como papilas para distingui-los dos tricomas presentes na região areolar. Os autores mencionam ainda que as papilas epidérmicas são comumente utilizadas na caracterização taxonômica de alguns grupos como, por exemplo, o reconhecimento de espécies de Opuntia. No presente estudo, optamos por descrever essas estruturas encontradas na epiderme de $O$. microdasys como papilas, seguindo a definição de Fahn (1990), o qual descreveu que as papilas são tricomas não-glandulares unisseriados, unicelulares ou multicelulares. Ainda segundo o autor, essas papilas podem atuar na captação de energia luminosa que é bastante limitada em plantas que crescem em ambientes sombreados. Nas plantas do presente trabalho, geralmente distribuídas em ambientes desérticos, estes tricomas parecem estar envolvidos com a redução da perda de água e favorecimento de um microclima para a abertura dos estômatos (Gibson \& Nobel 1986).

Um importante caráter taxonômico para a subfamília Opuntioideae são os estômatos, os quais, de acordo com Eggli (1984) são classificados como "opuntioid", caracterizando-se pela presença de
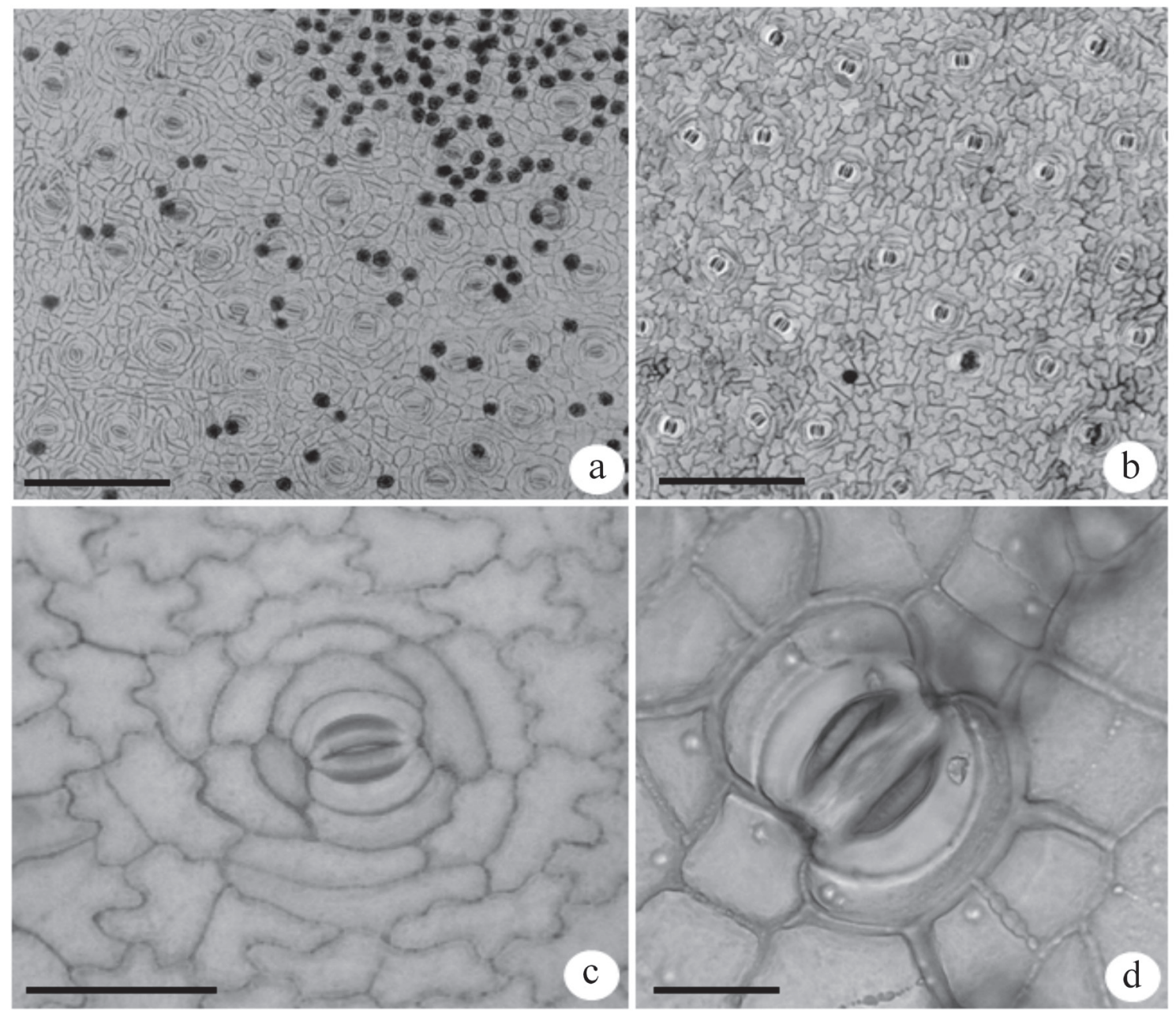

Figura 2. Vista frontal da epiderme do segmento caulinar. a-b. Células da epiderme com paredes retas em Austrocylindropuntia subulata (a) e Opuntia rufida (b). c. Células epidérmicas com paredes sinuosas e estômato hexacítico em Opuntia monacantha. d. Detalhe do estômato paracítico de Opuntia rufida. Barras $=80 \mu \mathrm{m}(\mathrm{a}-\mathrm{b}) ; 40 \mu \mathrm{m}$ (c-d).

Figure 2. Surface view of the epidermis in the stem segments. a-b. Epidermis with straight cell walls in Austrocylindropuntia subulata (a) and Opuntia rufida (b), respectively. c. Epidermis with wavy cell walls and hexacytic stomata in Opuntia monacantha. d. Details of the paracytic stomata in Opuntia rufida. Bars $=80 \mu \mathrm{m}$ (a-b); $40 \mu \mathrm{m}$ (c-d). 
número indeterminado de células subsidiárias em volta das células-guarda. Nas espécies estudadas, os tipos estomáticos observados foram hexacítico em A. subulata e $O$. monacantha, e paracíticos nas demais espécies estudadas (tabela 1, figura 2a-f), seguindo a classificação de Fryns-Claessens \& Van-Cothem (1973). Em Cactoideae, Loza-Cornejo \& Terrazas (2003) mencionaram que todas as 70 espécies de 21 gêneros estudados apresentam o tipo paralelocítico, podendo representar um importante caráter taxonômico para a subfamília. Em Opuntioideae, embora o número de espécies estudadas, até o momento, seja bastante limitado, os resultados mostram que há apenas dois tipos de estômatos, os hexacítico e paracítico. Com as informações disponíveis, ainda não é possível inferir quanto à importância deste caráter nas relações filogenéticas das duas subfamílias.

Em vista frontal, as células epidérmicas apresentam paredes retas em A. subulata e O. microdasys e sinuosas apenas em $O$. monacantha (figuras 2a-f). Já em $O$. rufida, as paredes das células epidérmicas são sinuosas apenas no ápice e retas nas regiões medianas e basais. Infelizmente, este caráter não foi analisado em outras espécies de Opuntioideae (tabela 1), impossibilitando qualquer discussão no grupo. No entanto, vale salientar que em Cactoideae, este é um aspecto que vem revelando importantes ferramentas taxonômicas (Loza-Conejo \& Terrazas 2003, Calvente et al. 2008) e que, em alguns grupos, se apresenta variável durante o desenvolvimento dos segmentos caulinares (Lemos \& Melo-de-Pinna 2011).

$\mathrm{Na}$ região basal do segmento caulinar de todas as espécies analisadas, a epiderme é substituída pela periderme (figura 3a), com felogênio instalando-se a partir da camada epidérmica ou de camadas subepidérmicas, semelhante ao descrito em outras espécies da família (Gibson \& Nobel 1986, Mauseth 1999, Soffiatti \& Angyalossy 2003).

A família Cactaceae apresenta inúmeras características morfoanatômicas, tais como: elevada frequência
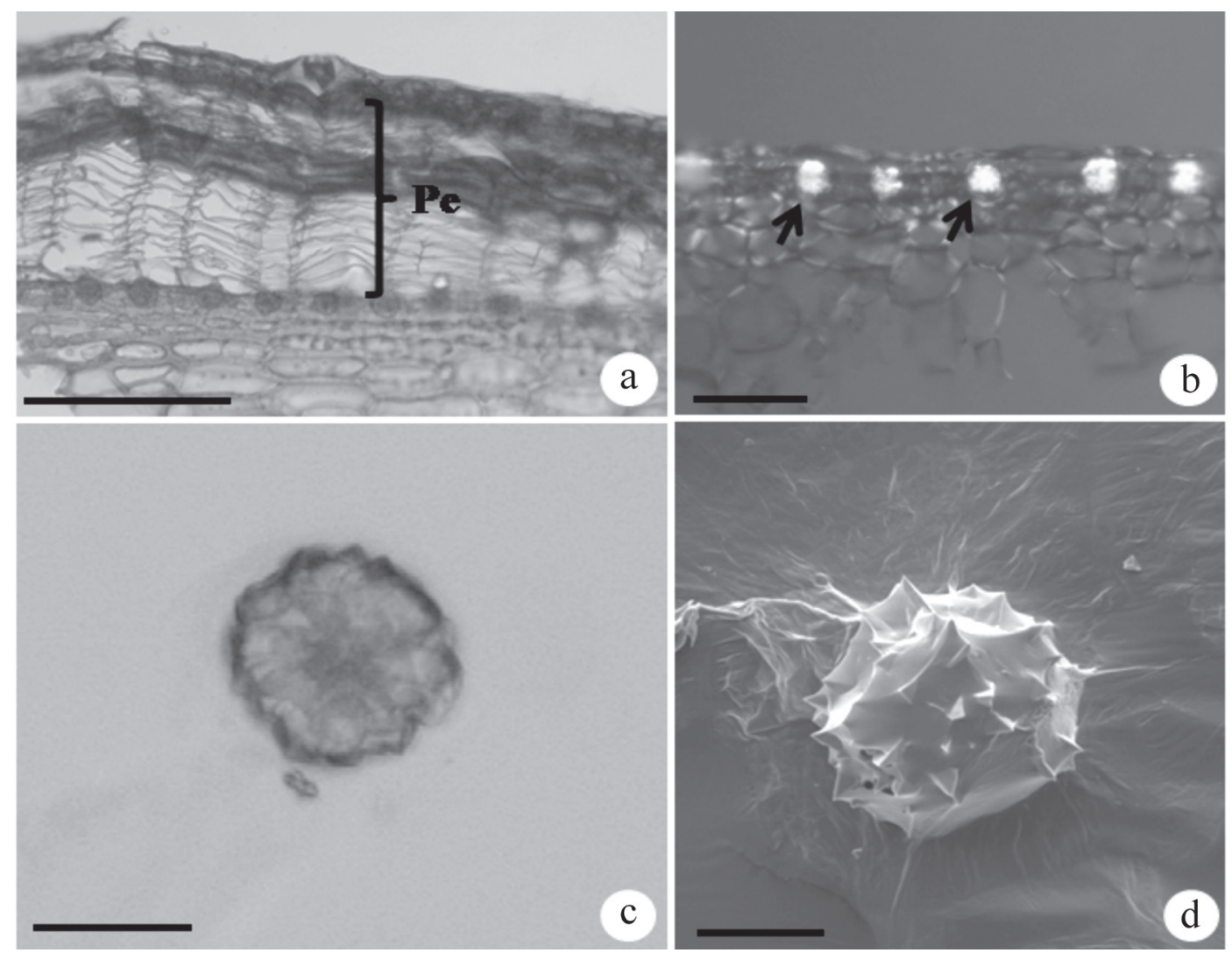

Figura 3. a-b. Secções transversais do segmento caulinar. a. Base do segmento caulinar de Opuntia monacantha, periderme (Pe). b. Austrocylindropuntia subulata, hipoderme colenquimática com drusas (seta) em luz polarizada. c-d. Drusas hipodérmicas em microscopia óptica e Microscopia Eletrônica de Varredura (MEV), respectivamente. Barras = $150 \mu \mathrm{m}$ (a); $350 \mu \mathrm{m}$ (b); $50 \mu \mathrm{m}$ (c); 1 mm (d).

Figure 3. a-b. Cross sections of the stem segments. a. Base of the stem segment in Opuntia monacantha showing the peridermis (Pe). b. Austrocylindropuntia subulata showing the collenchymatic hypodermis with druses (arrow) in polarizing light microscopy. c-d. Hypodermic druses in optical microscopy and Scanning Electron Microscopy (SEM), respectively. Bars = $150 \mu \mathrm{m}$ (a); $350 \mu \mathrm{m}$ (b); $50 \mu \mathrm{m}$ (c); $1 \mathrm{~mm}$ (d). 
estomática, presença de córtex paliçádico, grande quantidade de espaços intercelulares, feixes corticais e medulares, modificações no lenho que atuam como importantes adaptações às condições áridas onde a maioria dos representantes da família é encontrada (Gibson \& Nobel 1986, Nobel 2002). Entretanto, uma das mais importantes características do ponto de vista adaptativo e taxonômico trata-se do skin, que consiste da epiderme juntamente com a hipoderme (Bailey 1961, Gibson \& Nobel 1986, Darling 1989) uma vez que é a camada mais externa representando o limite com o ambiente externo.

O sistema fundamental é formado externamente pela hipoderme (figuras 1a-b, 3a-b), que em todas as regiões analisadas (ápice, meio e base), é multisseriada. O número de camadas é bastante variável dentre as espécies estudadas, sendo: 3-4 camadas em $O$. rufida; 2-3 em O. microdasys; 3-5 em O. monacantha e 8-10 em $A$. subulata.

$\mathrm{Na}$ literatura atual, a hipoderme vem sendo descrita em várias espécies de Cactaceae e tem recebido diferentes terminologias: hipoderme colenquimática (Loza-Cornejo \& Terrazas 2003, Soffiatti \& Angyalossy 2003, Yoshikawa et al. 2004, Arruda et al. 2005, Godofredo \& Melo-de-Pinna 2008) ou pseudo-hipoderme colenquimatosa (Metcalfe \& Chalk 1950). A hipoderme colenquimática é descrita na maioria das Opuntioideae e Cactoideae, estando ausente em gêneros basais da subfamília Cactoideae como Blossfeldia Werderm. (Mauseth 2006) e Gymnocalycium Pfeiff. (Gibson \& Horak 1978).

Nas espécies analisadas as células da hipoderme apresentam espessamento anelar de parede primária (figuras 1a-b). Na hipoderme de Cactaceae as células podem apresentar paredes com diferentes padrões de espessamento, como anelar (típico de Opuntioideae) ou lamelar com o lume irregular, conforme verificado em espécies de Cactoideae (Loza-Cornejo \& Terrazas 2003, Arruda et al. 2005). Diferenças nos tipos de espessamento das paredes das células da hipoderme são mencionadas por outros autores para representantes
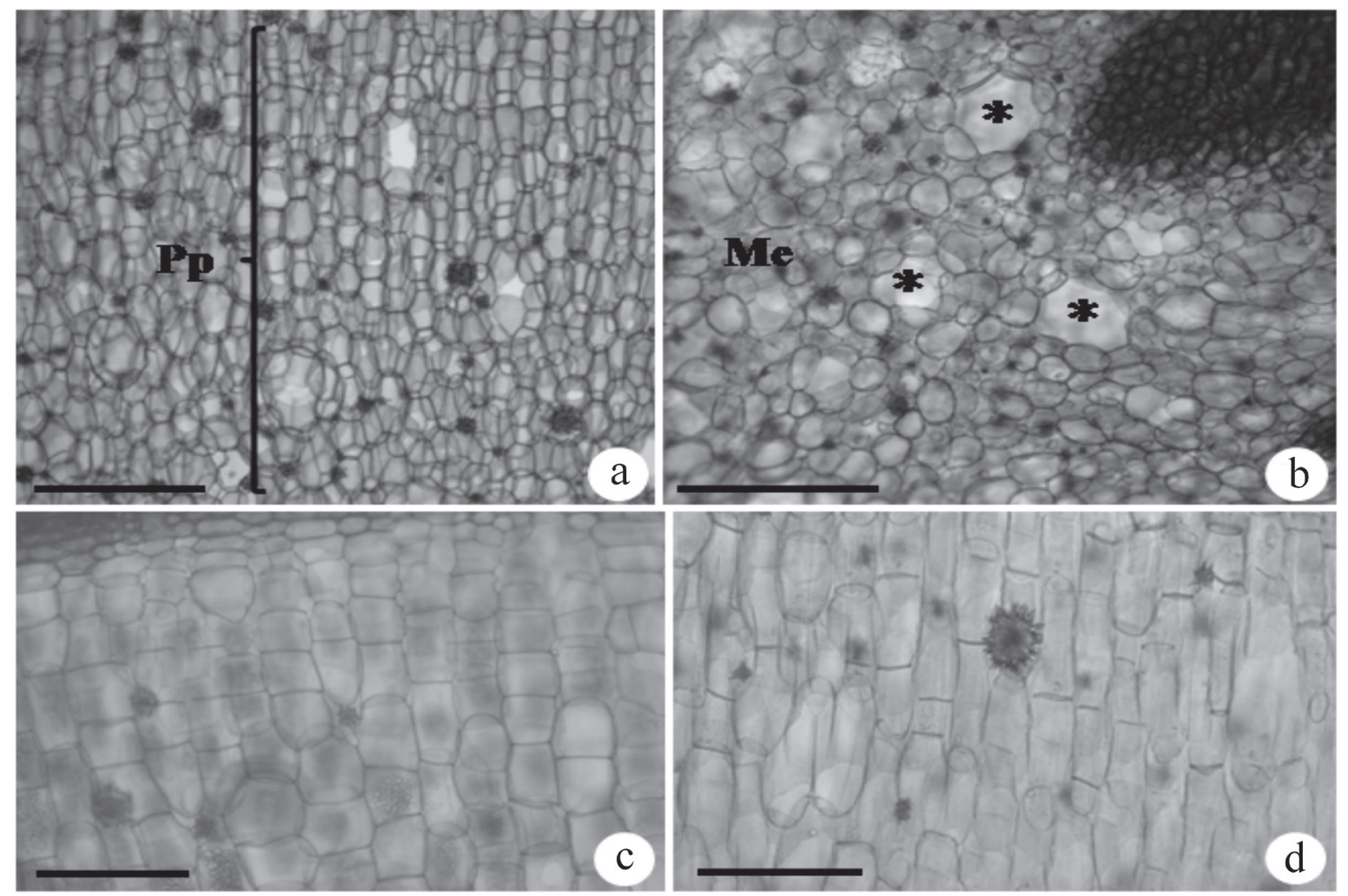

Figura 4. Secções transversais do segmento caulinar. a. Região cortical, mostrando o parênquima paliçádico (Pp) em Opuntia rufida. b. Região medular (Me) em Austrocylindropuntia subulata, em Opuntia rufida (c) e Opuntia microdasys (d). Barras = $350 \mu \mathrm{m}$ (a-b); $150 \mu \mathrm{m}$ (c-d).

Figure 4. Cross sections of the stem segments. a. Cortical region showing the palisade parenchyma (Pp) in Opuntia rufida. b. Medullary region (Me) in Austrocylindropuntia subulata. Note secretory cavities of mucilage (*). c-d. Palisade parenchyma in Opuntia microdasys and Opuntia monacantha, respectively. Bars $=350 \mu \mathrm{m}(\mathrm{a}-\mathrm{b}) ; 150 \mu \mathrm{m}(\mathrm{c}-\mathrm{d})$. 
das subfamílias Opuntioideae e Cactoideae (Soffiatti \& Angyalossy 2003, Arruda et al. 2005).

Ainda na hipoderme, são observadas drusas com distribuição contínua na primeira camada de células da hipoderme, imediatamente interna à epiderme (figuras 3a-d). Esta distribuição das drusas na hipoderme também é descrita na literatura para outros representantes de Opuntioideae (Gibson \& Nobel 1986). Em Cactaceae há diferentes tipos de cristais, como por exemplo, em Cactoideae os cristais podem ser prismáticos ou agregados, como as drusas (Bailey 1961, Gibson \& Nobel 1986, Loza-Cornejo \& Terrazas 2003). Em Opuntioideae, no entanto, os cristais são agregados do tipo drusa, e sua utilização na taxonomia é mais limitada, embora possa haver diferentes subtipos quanto ao aspecto geral dessas estruturas (Gibson \& Nobel 1986, Nobel 2002).

O parênquima cortical está subdividido em parênquima externo clorofiliano, cujas células são alongadas, sendo caracterizado como parênquima paliçádico e uma porção mais interna constituída por células isodiamétricas, descrita como parênquima armazenador, compreendendo parte do córtex interno e da medula (figuras 4a-d). As células do parênquima clorofiliano, em seção transversal, são quadrangulares em $A$. subulata e $O$. monacantha
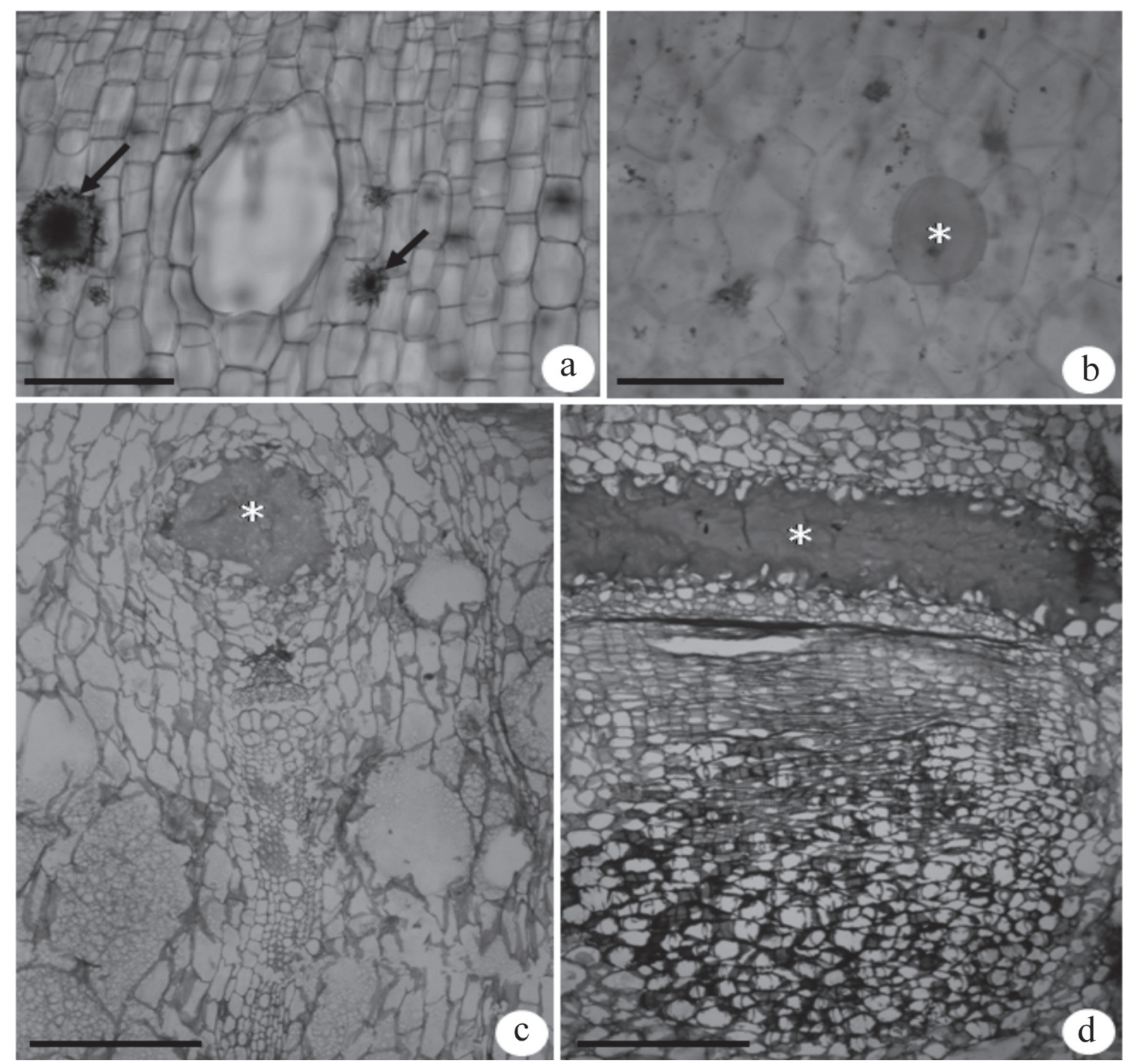

Figura 5. a-c. Secções transversais do segmento caulinar. a. Cavidade secretora de mucilagem em Opuntia monacantha, drusas no parênquima cortical (setas). b. Célula secretora de mucilagem $\left(^{*}\right)$ em Opuntia rufida. c-d. Canal secretor de mucilagem em Opuntia microdasys na região pericíclica em secção transversal (c) e longitudinal (d). Barras $=150 \mu \mathrm{m}$ (a-b); $350 \mu \mathrm{m}$ (c-d).

Figure 5. a-c. Cross sections of the stem segment. a. Secretory cavities of mucilage in Opuntia monacantha. Note druses in the cortical parenchyma (arrow). b. Secretory cells of mucilage $(*)$ in Opuntia rufida. c-d. Secretory channel of mucilage in pericyclic region of Opuntia microdasys, in cross (c) and longitudinal sections (d). Bars $=150 \mu \mathrm{m}(\mathrm{a}-\mathrm{b}) ; 350 \mu \mathrm{m}$ (c-d). 
(figura 4c) e retangulares em $O$. rufida e $O$. microdasys (figura 4d). Quanto ao número de camadas de células, o parênquima clorofiliano apresenta de 4-6 camadas em O. rufida; 5-8 em O. monacantha; 7-8 em A. subulata e 6-8 camadas em O. microdasys.

Esta subdivisão do parênquima cortical é mencionada em outras espécies das subfamílias Opuntioideae e Cactoideae (Metcalfe \& Chalk 1950, Gibson \& Nobel 1986, Mauseth \& Ross 1988, Arruda et al. 2005). Sajeva \& Mauseth (1991) por meio de um estudo comparativo entre caules de Pereskia e espécies de Cactoideae, verificaram que o caule destes dois grupos mostra-se bastante diferente do ponto de vista anatômico. Os autores observaram muitas modificações relacionadas às trocas gasosas e a realização do processo fotossintético, que são consideradas derivadas em Cactoideae, sendo uma delas a subdivisão do parênquima cortical, como observado no presente estudo. Embora em Opuntioideae estudos explicando esta função ainda não tenham sido feitos, talvez o a subdivisão do parênquima cortical possa estar envolvida no mesmo processo.

No parênquima armazenador estão presentes ainda células, canais e cavidades secretoras de mucilagem (figuras 4a-b e 5a-d). Células e cavidades ocorrem em todas as espécies estudadas, enquanto que canais secretores foram observados apenas em O. rufida e O. microdasys (Opuntieae, figuras 5c-d).
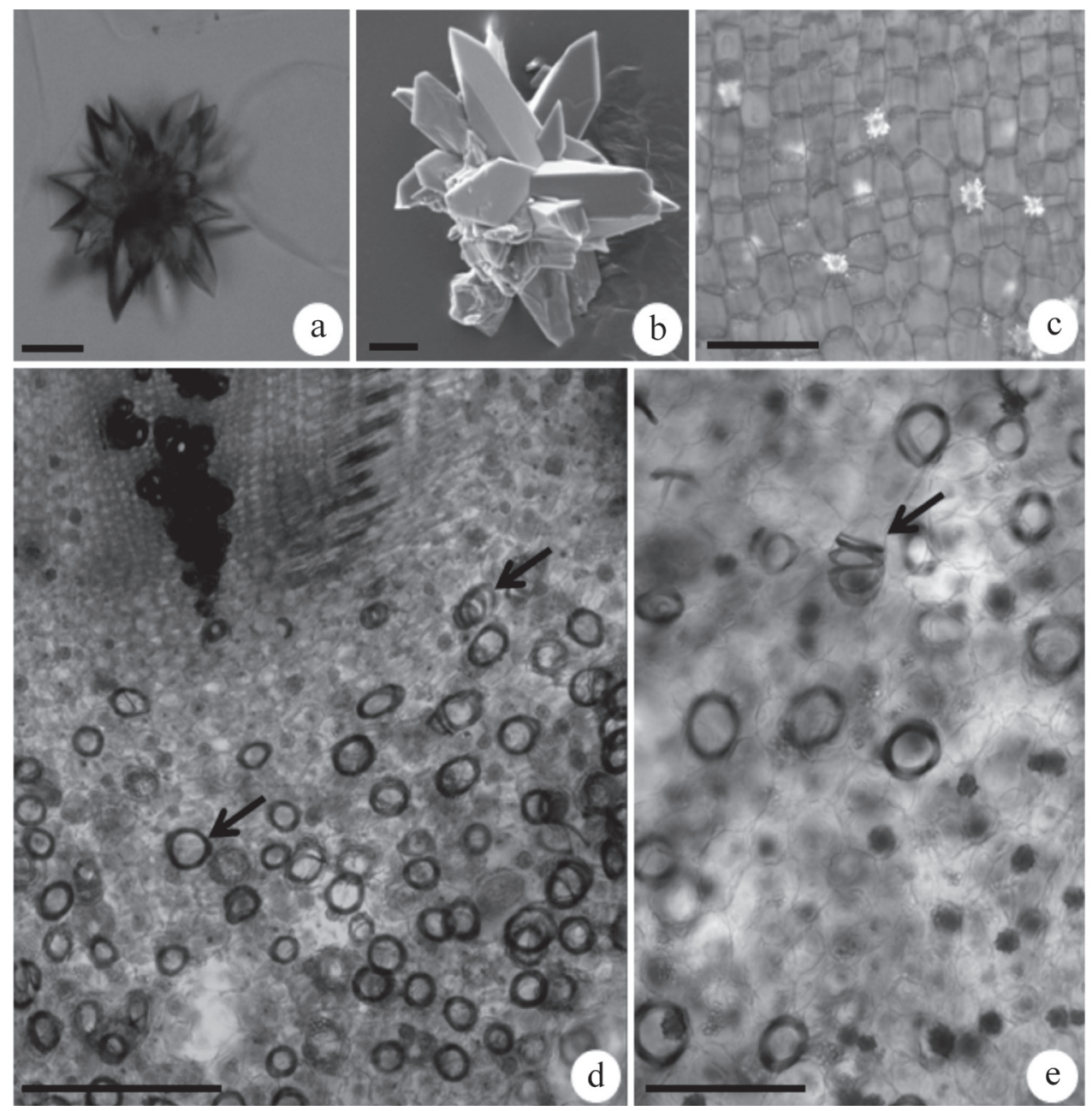

Figura 6. a-b. Detalhes de drusas presentes nas regiões cortical e medular do segmento caulinar de Austrocylindropuntia subulata, em microscopia óptica (a) e Microscopia Eletrônica de Varredura (b). c-e. Secções transversais do segmento caulinar. c. Região cortical de Opuntia rufida, drusas em luz polarizada. d-e. Região medular de Opuntia monacantha, costomestulas comento de parede secundária semelhantes às traqueídes vasculares (setas). Barras $=50 \mu \mathrm{m}$ (a);35 $\mu \mathrm{m}$ (b); $150 \mu \mathrm{m}$ (c); $350 \mu \mathrm{m}$ (d); $40 \mu \mathrm{m}$ (e).

Figure 6. a-b. Details of druses in the cortical and medullar regions of the stem segments of Austrocylindropuntia subulata in optical microscopy and Scanning Electron Microscopy (SEM), respectively. c-e. Cross sections of the stem segments. c. Cortical region of Opuntia rufida showing druses in polarizing light microscopy. d-e. Medullary region of Opuntia monacantha showing cells with secondary thickened wall similar to vascular tracheids (arrow). Bars $=50 \mu \mathrm{m}$ (a); $35 \mu \mathrm{m}$ (b); $150 \mu \mathrm{m}$ (c); $350 \mu \mathrm{m}$ (d); $40 \mu \mathrm{m}$ (e). 
Estes canais secretores têm distribuição restrita às regiões medianas e basais do segmento caulinar, localizando-se na região pericíclica adjacente ao floema primário (figuras $5 \mathrm{c}-\mathrm{d}$ ).

Ainda no sistema fundamental foi possível observar drusas (figuras 6a-e) no parênquima cortical e no medular, estando mais concentradas quando adjacentes às cavidades secretoras de mucilagem em $O$. microdasys e $O$. monacantha, e próximo ao floema como em todas as espécies estudadas neste trabalho. Essas drusas se diferenciam morfologicamente daquelas presentes na hipoderme, especialmente quanto ao comprimento das projeções dos cristais. De acordo com Gibson \& Nobel (1986) o formato das drusas está relacionado à natureza da parede celular. Isto pode explicar a presença de drusas "arredondadas" na hipoderme, cuja parede primária é mais espessada impedindo ou limitando o prolongamento das projeções do cristal; enquanto que drusas "pontiagudas" ocorrem no sistema fundamental cujas células parenquimáticas apresentam paredes mais delgadas permitindo o prolongamento dos cristais que compõem a drusa.

$\mathrm{Na}$ região medular do sistema fundamental ocorrem células e cavidades mucilaginosas (figura 4b). Além dessas estruturas, em $O$. monacantha foram observadas também células com espessamento de parede secundária, semelhantes às traqueídes vasculares com amplo espessamento de parede, descritas na literatura como wide-band tracheids ou simplesmente, WBTs (figuras 6d-e). Em Opuntioideae, células com características muito semelhantes às observadas em $O$. monacantha, são descritas como traqueídes perimedulares, pois ocorrem adjacentes ao xilema primário, em regiões mais externas da medula (Conde 1975, Mauseth 2006). A ampla distribuição na região medular, deste tipo especial de traqueíde em O. monacantha, representa o primeiro registro para a família Cactaceae.

Concluindo, alguns caracteres descritos no presente estudo representam o primeiro registro na literatura de Opuntiodeae, como: posição dos estômatos, aspecto geral das células do parênquima paliçádico e as células medulares com espessamento de parede secundária. Somado a isto, os dados anatômicos obtidos podem ser informativos na delimitação das espécies estudadas.

\section{Agradecimentos}

Agradecemos à Fundação de Amparo à Pesquisa do Estado de São Paulo - FAPESP (Processo
06/58023-2, 09/14708-0) e ao Conselho Nacional de Desenvolvimento Científico e Tecnológico - CNPq (Processo 305267/2006, GM/GD 142111/2006-6), pelo apoio financeiro para o desenvolvimento da pesquisa. Os autores agradecem ainda ao MSc. Marlon Machado da Universidade Estadual de Feira de Santana, Bahia, pela identificação das espécies.

\section{Literatura citada}

Anderson, E.F. 2001. The cactus family. Timber Press, Portland, Oregon.

Arruda, E., Melo-de-Pinna, G.F. \& Alves, M. 2005. Anatomia dos órgãos vegetativos de Cactaceae da caatinga pernambucana. Revista Brasileira de Botânica 28: 589-601.

Bailey, I.W. 1961. Comparative anatomy of the leafbearing Cactaceae, II. Foliar vasculature of Pereskia, Pereskiopsis and Quiabentia. Journal Arnold Arboretum 43: 376-383.

Calvente, A.M., Andreata, R.H.P. \& Vieira, R.C. 2008. Stem anatomy of Rhipsalis (Cactaceae) and its relevance for taxonomy. Plant Systematic and Evolution 276: 1-7.

Conde, L. 1975. Anatomical comparisons of five species of Opuntia (Cactaceae). Annals of Missouri Botanical Garden 62: 125-173.

Darling, M. 1989. Epidermis and hypodermis of saguaro cactus (Cereus giganteus): Anatomy and spectral properties. American Journal of Botany 76: 1698-1706.

Eggli, U. 1984. Stomatal types of Cactaceae. Plant Systematics and Evolution 146: 197-214.

Fahn, A. 1990. Plant anatomy. 4 ed. Pergamon Press, Oxford.

Fahn, A. \& Cutler, D. 1992. Xerophytes. Gubruder Borntraeger, Berlin.

Franklin, G. 1945. Preparation of thin sections of synthetic resins and wood - resin composites and a new macerating method for wood. Nature 155: 51.

Fryns-Claessens, E. \& Van-Cothem, W. 1973. A new classification of the ontogenetic types of stomata. The Botanical Review 39: 71-138.

Gibson, A.C. \& Horak, K. 1978. Systematic anatomy and phylogeny of Mexican cacti. Annals of Missouri Botanical Garden 65: 999-1057.

Gibson, A.C. \& Nobel, P. 1986. The cactus primer. Haward University Press, Cambridge.

Godofredo, V.R. \& Melo-de-Pinna, G.F.A. 2008. Occurrence of wide-band tracheids in Cactaceae: wood variation during Pilosocereus aurisetus development. Journal Torrey of Botanical Society 135: 94-102.

Griffith, M.P. \& Porter, M. 2009. Phylogeny of Opuntioideae. International Journal of Plant Science 170:107-116. 
Hamilton, A. 1970. The comparative morphology of three cylindropuntias. American Journal of Botany 57: $1255-1263$.

Johansen, D. 1940. Plant microtechnic. Mc Grow Hill Book Company, Inc., New York.

Kraus, J.E., Sousa, H.C., Rezende, M.H., Castro, N.M., Vecchi, C. \& Luque, R. 1998. Astra blue and basic fucsin double staining of plant materials. Biotechnic and Histochemistry 73:235-243.

Lemos, R.C.C. \& Melo-de-Pinna, G.F.A. 2011. Morphoanatomical variations during stem development in some epiphytic Cactaceae. Journal of TorreyBotanical Society 138: 16-25.

Loza-Cornejo, S. \& Terrazas, T. 2003. Epidermal and hypodermal characteristics in North American cactoideae (Cactaceae). Journal of Plant Research 11: 27-35.

Mauseth, J. 1996. Comparative anatomy of tribes Cereeae, Browningeae (Cactaceae). Bradleya 14: 66-81.

Mauseth, J. 1999. Comparative anatomy of Espostoa, Pseudoespostoa, Thrixanthocereus and Vatricania (Cactaceae). Bradleya 17: 27-37.

Mauseth, J. 2006. Blossfeldia lacks cortical bundles and persistent epidermis; is it basal within Cactoideae? Bradleya 24: 73-82.

Mauseth, J. \& Ross, R. 1988. Systematic anatomy of the primitive cereoid cactus Leptocereus quadricostatus. Bradleya 6: 49-64.

Metcalfe, C.R. \& Chalk, L. 1950. Anatomy of the dicotyledons. Clarendon Press, Oxford.
Nobel, P.S. 2002. Cacti: biology and uses. University of Califórnia Press, Berkeley.

Pizzolato, T.D. \& Lillie, R.D. 1973. Mayer's tannic acid-ferric chloride stain for mucins. Journal of Histochemistry and Cytochemistry 21: 56-64.

Purvis, M., Collier, D. \& Walls, D. 1964. Laboratory techniques in botany. Butterworths, London.

Sajeva, M. \& Mauseth, J. 1991. Leaf-like structure in the photosynthetic, succulent stems of cacti. Annals of Botany 68: 405-411.

Silveira, M. 1989. Preparação de amostras biológicas para Microscopia eletrônica de varredura. In: W Souza (ed.). Manual sobre técnicas básicas de microscopia eletrônica. Universidade de São Paulo, São Paulo v. 1, pp. 71-79.

Terrazas, T. \& Arias, S. 2003. Comparative stem anatomy in the subfamily Cactoideae. The Botanical Review 68: 444-473.

Wallace, R.S. \& Dickie, S.L. 2002. Systematic implications of chloroplast DNA sequence variation in the Opuntioideae. In: D. Hunt \& N. Taylor (eds.). Studies in the Opuntioideae. Milborne Port Sherbone, England.

Yoshikawa, R.C.S., Soffiatti, P. \& Angyalossy, V. 2004. Stem and root anatomy of Melocactus bahiensis and Melocactus concinnus (Cactaceae, Subfamília Cactoideae, Tribe Cereeae). Revista de Biologia Neotropical 27: 45-52. 